\title{
Hepatitis B as a hazard to laboratory staff: a re-appraisal
}

\author{
EAC FOLLETT AND JD SLEIGH \\ From the Hepatitis Reference Laboratory, Ruchill Hospital, Glasgow G20 9NB \\ and the Department of Bacteriology, Royal Infirmary, Glasgow G4 OSF, Scotland
}

\section{Present status}

Hepatitis B virus is a category B pathogen, by definition offering special hazards to laboratory workers. ${ }^{1}$

Specialist laboratories deliberately testing for hepatitis B virus or hepatitis B surface antigen ( $\mathrm{HBsAg})$ are required to treat the virus as a B1 pathogen and to provide special accommodation and conditions for containment. Other laboratories are allowed in the Code of Practice for the Prevention of Infection in Clinical Laboratories ${ }^{1}$ to consider hepatitis B virus in category B2; this permits specimens to be handled in an ordinary laboratory but places restrictions on the reception, testing, and disposal of such specimens. Specimens received from groups believed to be 'at risk' of suffering from hepatitis B virus infection are also included in B2, and similar restrictions are placed on these specimens.

\section{Difficulties and anomalies of present status}

1 It is stipulated in the Code of Practice that B1 or B2 specimens must be processed singly or in batches separate from other specimens, for example, at the end of a session. Batching of B2 specimens in this way is not always acceptable by either the clinician or the laboratory. If a result is required urgently for a B2 specimen it must be processed singly, and if the Code of Practice is followed to the letter any machinery used, for example, in biochemistry or haematology, must then be disinfected with hypochlorite or glutaraldehyde before any further work is undertaken (paragraph 25b, 26b). In all but the smallest laboratories this results in a total upset of working schedules, especially as B2 specimens are likely to be received randomly throughout the day.

2 Certain biochemical analysers cannot be disinfected with either hypochlorite or glutaraldehyde. Theoretically, B2 specimens cannot be

Received for publication 30 June 1980 processed on these machines. In practice, unknown B2 specimens must be handled regularly in these machines (approx 1 in 800 volunteer blood donors in the UK are HBsAg carriers). ${ }^{2}{ }^{3}$ The Code of Practice offers no advice on the procedure to be followed when it is subsequently found that a specimen already processed was in category B2.

3 It is impossible to select $\mathrm{HBsAg}$ carriers from general hospital patients without testing all patients for HBsAg. The medical history may be of little help (eg, most HBsAg carriers are totally asymptomatic and give no history of jaundice/hepatitis). ${ }^{4}$ Biochemical tests may be misleading (most HBsAg carriers have no evidence of abnormal liver function). ${ }^{5}$ Therefore, a minimum of 1 in 800 of all patients in a general hospital will be an HBsAg carrier and, unless previously a blood donor, will be unaware of his/her status, as will the hospital staff. Specimens from such a patient will be processed as category $\mathrm{C}$.

4 The selection of 'at risk' groups is particularly difficult. Drug addicts and the homosexually and heterosexually promiscuous are known to have a much higher prevalence of hepatitis B virus markers than the normal population. ${ }^{6-8}$ Should all new inpatients be so questioned? Even if they were, would the answer be reliable? Would such questioning lead to the possibility of extremely confidential information passing through too many hands? Should a patient with a broken leg be asked about his/her sexual/social activities?

Jaundiced patients are a particular problem. The vast majority do not have a hepatitis $B$ infection, but too many are labelled with a danger of infection tag. Specimens from these patients cause anxiety to the laboratory and, more seriously, delay in carrying out the requested tests and sending the results to the clinician. In addition, many biochemical and haematology laboratories offer only a minimum essential service on category $\mathbf{B} 2$ specimens. The patient given a B2 label, possibly for historical or anecdotal reasons, is automatically a second-class patient not receiving the full benefits of modern 
biochemical and haematological technology.

5 The Code of Practice recommends uniform measures to reduce infection by category $B$ pathogens without identifying the source and mode of spread of the pathogen. For example, it lays down that centrifugation of all category $\mathrm{B} 1$ and $\mathrm{B} 2$ specimens must be carried out in labelled, screw-capped containers within sealed centrifuge buckets that have to be opened in an exhaust protective cabinet. Such measures are to protect against the aerosolinhalation route of infection whereas hepatitis B is most commonly transmitted by the parenteral route. Aerosol and droplet infection is a very unusual route of transmission, and present evidence indicates that it is inefficient. Experiments to infect chimpanzees by the aerosol route with material proved to be infective by the parenteral route have been unsuccessful. ${ }^{9}$ Biochemistry and haematology laboratories do not process sputum specimens, and it thus seems an unnecessary expense to require the purchase of class I cabinets by all such laboratories to protect against an aerosol route of transmission for hepatitis B virus.

\section{Hazard to laboratory workers}

By definition, category $\mathbf{B}$ pathogens are those that present a hazard to laboratory workers. How serious is this hazard?

1 Laboratory workers handle blood and blood components. Blood is the most effective agent for transmitting hepatitis B virus. Therefore, there is no doubt that laboratory staff must be at greater risk of exposure to hepatitis B virus than the general population.

2 Hepatitis B infection does occur in laboratory staff. The continuing survey by the Association of Clinical Pathologists ${ }^{1 \mathrm{~s}-10}$ and the report of Harrington and Shannon ${ }^{14}$ document cases in laboratory staff. However, it is very important to remember that the figures of Harrington and Shannon were for 1971 or 1973 and those of the Association show a noticeable decline since 1975 (Table 1). In addition, the figures

Table 1 Hepatitis $B$ infection in laboratory staff*

\begin{tabular}{lllll}
\hline Years & $\begin{array}{l}\text { No. of } \\
\text { cases }\end{array}$ & $\begin{array}{l}\text { Annual } \\
\text { average }\end{array}$ & $\begin{array}{l}\text { Estimated No. } \\
\text { at risk }\end{array}$ & $\begin{array}{l}\text { Attack } \\
\text { rate† }\end{array}$ \\
\hline $1970-72$ & 17 & $5 \cdot 66$ & 36893 & 111 \\
$1973-74$ & 14 & 7.0 & 22243 & 143 \\
$1975-76$ & 3 & 1.5 & 23142 & 35 \\
$1977-78$ & 6 & 3.0 & 27175 & 29 \\
\hline
\end{tabular}

*Figures from Grist ${ }^{12}$ with additional 1977-78 data from Grist. ${ }^{13}$ †Per 100000 person-years hepatitis due to all causes.

of Harrington and Shannon were for hepatitis due to all causes, not solely hepatitis $B$ virus.

Although the number of cases per year has re- mained almost static since 1975 the number of staff employed, and especially the number of specimens processed, has increased dramatically. Therefore, it can be concluded that hepatitis $B$ infection in laboratory staff is declining. Polakoff ${ }^{15}$ has also published figures for hepatitis B infection in laboratory staff in England, Wales, and Northern Ireland from 1972 (Table 2). These are taken from returns

Table 2 Hepatitis $B$ infection in laboratory staff in England, Wales, and Northern Ireland

\begin{tabular}{llc}
\hline $\begin{array}{l}\text { Epidemiological year } \\
\text { weeks } 27-26 \text { incl. }\end{array}$ & \multicolumn{2}{l}{$C D R$ reports of acute hepatitis $B$} \\
\cline { 2 - 3 } & No. of laboratory* staff & Total number \\
\hline $1972-$ & 8 & 681 \\
$1973-$ & 9 & 779 \\
$1974-$ & 7 & 913 \\
$1975-$ & 3 & 1061 \\
$1976-$ & 3 & 1067 \\
$1977-$ & 4 & 1223 \\
$1978-79$ & 3 & 980 \\
\hline
\end{tabular}

*Includes all categories working in laboratories: medical, scientific, technical, and ancillary.

Data from Polakoff, Communicable Disease Report 79/48 ${ }^{15}$

of all hepatitis B infections sent to the Communicable Diseases Centre, Colindale, and cover a more extensive population than the Association survey and can be taken as particularly reliable after 1975 when hepatitis B virus infection was legally defined as an industrial disease. ${ }^{15}$ Two points are particularly worthy of note: (i) These independently acquiredo data also show a dramatic drop, from 1975 onwards, in the number of laboratory personnel affected. (ii) Cases in laboratory staff are a tiny fraction (approx $0.3 \%$ ) of the total number reported. Cases of infection in laboratory staff in Scotland, taken from returns to the Communicable Diseases Scotland Unit, have been added in Table 3 to give comprehensive data for the whole of the UK since 1975.

Table 3 Hepatitis $B$ infection in laboratory staff in $U K^{*}$

\begin{tabular}{ll}
\hline Epidemiological year & No. of cases \\
\hline $1975-$ & 3 \\
$1976-$ & 3 \\
$1977-$ & 5 \\
$1978-79$ & 4 \\
\hline
\end{tabular}

*Figures from Communicable Disease Report 79/4815 with additional Scottish data from records of Communicable Diseases Scotland Unit.

The conclusion from all these figures is that there is a small number of cases of hepatitis $B$ infection in laboratory staff per year. Are these few all acquired in the laboratory? Almost certainly not. In a population group of over $\mathbf{3 0 0 0 0}$ laboratory staff, which includes many young people, there must be cases of hepatitis B infection more likely to have been acquired socially than occupationally. Therefore, handling of all specimens with extreme care in ideal conditions could never result in complete elimination 
of hepatitis B infection in laboratory staff.

3 The status of hepatitis $B$ as a dangerous laboratory pathogen results mainly from the severe outbreak of hepatitis in the Edinburgh Royal Infirmary Renal Unit in 1969-70. In this outbreak there were 11 fatalities, but it must also be remembered that, as a rule, death is a very rare outcome of a hepatitis B infection. The Edinburgh outbreak was highly atypical. Out of 187 cases of acute hepatitis B infection in West Scotland in recent years there has been only one fatality. Immediately after the Edinburgh outbreak a programme of regular screening of staff and patients in renal units was introduced throughout the United Kingdom. This has proved a most effective control measure. Sporadic cases of hepatitis B infection do occur in renal units, but regular screening allows these to be identified long before clinical symptoms are discernible in the patient or spread of infection within or beyond the unit has occurred. Because of this regular screening renal unit blood specimens must be among the safest delivered to the laboratory.

4 Each specimen that is HBsAg positive does not present an equal risk of infection to laboratory staff. Present evidence indicates that specimens that are $\mathrm{HBs} \mathrm{Ag}$ positive and also e-antigen positive have a very much higher degree of infectivity than those that are HBsAg positive and have antibody (anti-e) to the e-antigen. ${ }^{16}$ In the West of Scotland fewer than $20 \%$ of $\mathrm{HBsAg}$ positive blood donors have circulating e-antigen. ${ }^{17}$ Practically, this means that only 1 in more than 4000 specimens from unscreened hospital patients is likely to transmit infection if accidentally inoculated.

\section{Solutions}

1 To eliminate totally hepatitis B infection as a laboratory hazard it would be necessary to identify all sera containing $\mathrm{HBs} \mathrm{Ag}$. This could be done only by screening all sera received in the diagnostic laboratory before allowing the required investigations to proceed. There is no short cut which would allow the asymptomatic HBsAg carrier patient to be identified. Such a total screening of all laboratory specimens would be very expensive and time consuming. Even if such a total screening were undertaken the problem of testing positive specimens would remain. To meet the conditions of the Code of Practice and also to permit an uninterrupted flow of work, duplicate equipment would be required in each laboratory. One set of equipment would be used for hepatitis $B$ negative (category $C$ ) specimens and the other set would be kept for hepatitis B positive specimens. This solution would be prohibitively expensive.
2 To overcome the difficulties produced by the Code of Practice the simplest solution would be to allow laboratories which handle hepatitis specimens as category B2 to downgrade hepatitis B virus to category $C$. This category is defined to include those viruses that offer no special potential hazards to laboratory workers provided that the high standards of microbiological technique and safety required in the Code of Practice are observed. The present small annual number of cases of hepatitis $B$ infection seen in laboratory staff is a very significant reduction over the numbers seen in the early 1970s and does not indicate that hepatitis B is a major infectious hazard. Clearly, there was a marked improvement before the implementation of the Code of Practice, and so small are the numbers of reported cases that it is difficult to anticipate any further reduction even with full implementation of the Code of Practice. All laboratory staff are now keenly aware of the possibility of hepatitis infection, and it is probably this awareness rather than official or unofficial Codes of Practice that has produced the improvement.

If hepatitis B virus is to be downgraded then this must be accompanied by an upgrading in general laboratory standards, especially in biochemistry and haematology. The Association of Clinical Pathologists survey consistently points to biochemistry and haematology laboratories as the major source of hepatitis $\mathbf{B}$ infections in staff. One contributory factor could be the very large number of specimens processed in such laboratories, but we are also of the opinion that too many biochemistry and haematology staff consider blood and blood components as another reagent and not as potentially hazardous material, a view also expressed by Cossart. ${ }^{18}$ Gloves are worn only for 'danger of infection' specimens. All specimens must be considered potentially dangerous, and staff should be encouraged to wear gloves when handling any specimen. A recent American study ${ }^{19}$ indicates that the primary mode of transmission of hepatitis B virus to laboratory staff is via hand contact with contaminated items. The portal of entry of the virus is through inapparent breaks in the skin. Disposable gloves can be awkward and may reduce speed but they must increase safety and they should be worn. One other likely mode of transmission in the laboratories is by skin puncture resulting in accidental inoculation. It seems sensible to reduce the use of needles, other sharps, and especially glass Pasteur pipettes wherever possible as plastic alternatives are available for the latter. It must be stressed that protection of the skin, and especially of broken skin, is a most effective preventive measure against hepatitis $B$ infection. In any technique where splashing is likely to occur, it is also important to protect the oral mucosa and the 
conjunctivae. However, it seems more sensible to modify the technique so that splashing does not occur.

One unfortunate outcome of the Code of Practice has been the division of laboratory specimens into categories of high and low risk with the further consequence of equating low risk with no risk. It must be emphasised to all laboratory staff that every specimen presents a risk and should be so regarded. It is known that certain viruses and organisms in laboratory specimens can cause infection. There may be others as yet unknown.

In a recent paper ${ }^{20}$ we note that Howie and Collins propose that hepatitis $B$ virus should now be downgraded to category $\mathrm{C}$ and that this is current practice in the USA. ${ }^{21}$ We are of the opinion that hepatitis B virus should still be regarded as a B1 pathogen in laboratories deliberately testing for the presence of markers of virus infection as such laboratories must process positive material daily and must receive a much higher percentage of positive specimens than a general hospital laboratory.

We thank Professor NR Grist for allowing us to quote his latest data before publication, Dr Sheila Polakoff for information, and other colleagues in biochemistry and haematology for discussion.

\section{References}

1 Code of Practice for the Prevention of Infection in Clinical Laboratories and Post-mortem Rooms. London: HMSO, 1978.

2 Barbara JAJ, Howell DR, Cleghorn TE, Cameron CH, Briggs M, Dane DS. A comparison of different methods of screening blood donations for HBsAg. Vox Sang 1977;32:4-9.

${ }^{3}$ Barr A, Dow BC, Macvarish I. HBsAg detection-results of a comparative large scale testing of blood donations. Med Lab Sci 1979;36:109-14.

4 Follett EAC, Barr A, Crawford RJ, Mitchell R. Viral hepatitis markers in blood donors and patients with a history of jaundice. Lancet $1980 ; \mathrm{i}: 246-9$.

s Szmuness W, Harley EJ, Prince AM. Intrafamilial spread of asymptomatic hepatitis B. Am J Med Sci 1975;270: 293-304.

- Seef LB, Zimmerman HJ, Wright EC, et al. Hepatitis disease in asymptomatic parenteral narcotic drug abusers. Am J Med Sci 1975;270:41.
' Lim KS, Wong T, Fulford KWM, Catterall RD, Briggs M, Dane DS. Role of sexual and non-sexual practices in the transmission of hepatitis B. Br J Vener Dis 1977;53: 190-2.

${ }^{8}$ Coleman JC, Evans BA, Thornton A, Zuckerman AJ. Homosexual hepatitis. J Infect 1979;1:61-6.

${ }^{9}$ Bancroft WH, Snitban R, Scott RM, et al. Transmission of hepatitis $B$ virus to gibbons by exposure to human saliva containing hepatitis B surface antigen. $J$ Infect Dis 1977;135:79-85.

${ }^{10}$ Grist NR. Hepatitis in clinical laboratories: a three-year survey. J Clin Pathol 1975;28:255-9.

${ }^{11}$ Grist NR. Hepatitis in clinical laboratories 1973-74. J Clin Pathol 1976;29:480-3.

${ }^{12}$ Grist NR. Hepatitis in clinical laboratories 1975-76. J Clin Pathol 1978;31:415-7.

${ }^{13}$ Grist NR. Hepatitis in clinical laboratories 1977-78. J Clin Pathol 1980;33:471-3.

14 Harrington JM, Shannon HS. Incidence of tuberculosis, hepatitis, brucellosis and shigellosis in British medical laboratory workers. Br Med J 1976;1:759-62.

15 Acute hepatitis B in laboratory staff: reports to the CDR during seven epidemiological years, mid 1972-79. Comm Dis Rep 1979;79/48.

${ }^{16}$ Miyakawa Y, Mayumi M. Characterization and clinical significance of HBeAg. In: Vyas GN, Cohen SN, Schmid R, eds. Proceedings of Second Symposium on Viral Hepatitis. Philadelphia: The Franklin Institute Press, 1978:193-201.

17 Dow BC, Macvarish I, Barr A, Crawford RJ, Mitchell R. Significance of tests for $\mathrm{HBeAg}$ and anti-HBe in $\mathrm{HBs} \mathrm{Ag}$ positive blood donors. $J$ Clin Pathol in press.

18 Cossart YE. Virus Hepatitis and its Control. London : Baillière Tindall, 1977.

19 Lauer JL, Van Drunen NA, Washburn JW, Balfour HH: Transmission of hepatitis B virus in clinical laboratory areas. $J$ Infect Dis 1979;140:513-76.

${ }^{20}$ Howie JW, Collins $\mathrm{CH}$. The Howie Code for preventing infection in clinical laboratories: comments on some general criticism and specific complaints. B Med J 1980; 1:1071-4.

${ }^{21}$ United States Department of Health Education and Welfare. Classification of Etiologic Agents on the Basis of Hazard. Atlanta: Center for Disease Control, 1974.

Requests for reprints to: Dr EAC Follett, Hepatitis Reference Laboratory, Regional Virus Laboratory, Ruchill Hospital, Glasgow G20 9NB, UK.

This article was submitted to the Joint Working Party on Safety in Clinical Laboratories of the Association of Clinical Biochemists, Association of Clinical Pathologists, Institute of Medical Laboratory Science, and Royal College of Pathologists as a discussion paper to enable a stated case to be drawn up to downgrade hepatitis $B$ virus from category $B 2$ to $C$. The stated case based on this information was subsequently sent to the Interim Advisory Committee of the Department of Health and Social Security. 